\title{
Polémicas
}




\section{LO SAGRADO AL ACECHO}

Notas sobre algunos comportamientos criptorreligiosos de la tribu Pedagógica (vivencias de un decano de la Universidad Pedagógica Nacional).

Rodolfo R. de Roux*

\section{Introito}

Al llegar a una universidad pública como la Universidad Pedagógica Nacional se piensa haber entrado en un santuario de la razón, lugar dedicado - como se supone que es cualquier universidad- a la búsqueda desprejuiciada y libre de la verdad, y al perfeccionamiento en el oficio de pensar.

Sin embargo, con el paso de los días y sin mucha dificultad, uno va observando comportamientos que hacen recordar el mundo de los adeptos religiosos, con sus creencias y rituales establecidos, autoridades consagradas, ortodoxias qué defender, misioneros de nuevas utopías, apóstoles del magisterio.

Al mostrar a los interesados las analogías entre ciertos comportamientos típicos de los creyentes religiosos y algunos comportamientos de grupos significativos de la UPN (incluidos alumnos), se muestran sorprendidos. Más aun cuando buena parte de ellos hace profesión de racionalismo o ateísmo. Lo cual me hace pensar que no dejamos de creer en algo para no creer en nada, sino para creer en otra cosa; o como sarcásticamente decía Chesterton: "desde cuando los hombres no creen más en Dios no es que no crean más en nada: creen en todo".

La anotada sorpresa también revela que estamos en el terreno de lo inconsciente. Me tomo, pues, este trabajo de "revelación" porque pienso que la peor filosofía es la implícita y tengo, en consecuencia, cierta inclinación por el nivel de la conciencia, aun a sabiendas de que en lo referente a comportamientos inconscientes no cabe esperar demasiado de la ilustración puramente intelectual y desde fuera. De todas formas, por insuficiente y poco eficaz que sea, es mejor un poco de ilustración que ninguna.

Cómo se manifiestan, qué esconden y qué revelan estos comportamientos a los que denomino "criptorreligiosos" son preguntas que guiarán mi reflexión. En un principio algunas cosas me parecían ridículas ( $\mathrm{y}$ tal vez lo sean), pero no hay que avergonzarse de ello. El hombre es el único animal capaz del ridículo. Por eso el filósofo está para las ridiculeces. Ya lo decía Platón en el Parménides. Trataré, pues, de atender tan sabia insinuación.

¿Cómo he hecho para saber lo que cuento aquí? A lo largo de dos años he participado activamente, como docente y decano, en la vida de la tribu Pedagógica, he observado sus actividades y comportamientos y he dedicado muchas horas a hablar con un apreciable número de sus miembros. Como dirían en jerga los investigadores, echaré mano de

\footnotetext{
${ }^{*}$ Historiador. Profesor universitario. Ex decano de la Facultad de Artes y Humanidades de la Universidad Pedagógica Nacional.
} 
múltiples observaciones participantes y no participantes, de entrevistas informales, charlas de corredor y de cafetería ${ }^{34}$ y de innumerables reuniones de trabajo, en su mayoría improductivas, pero que forman ya parte sustancial del ritual académico y a las que, mágicamente, como a los sacramentos cristianos, se las supone eficaces por virtud propia $^{35}$.

No voy a hacer de fiscal ni de apologeta; sólo trato de comprender. Lo cual no garantiza la imparcialidad ni me exime de la posibilidad de apreciaciones poco acertadas o de generalizaciones injustas. Confío en que el buen juicio del lector llenará las lagunas de este breve texto.

Utilizaré el ensayo, género en el que, por excelencia, uno corre el riesgo de lo peligrosamente personal y en el que se permite plantear preguntas que otros géneros tienden a olvidar.

En el ensayo la modestia de los resultados es proporcional a la amplitud de la ambición. Los problemas no son siempre precisos pero jamás son insignificantes. No pretende llegar a conclusiones irrefutables sino a proponer unas cuantas hipótesis. El ensayo elabora una estrategia frente a la incertidumbre: la puebla de imaginación teórica. Toda estrategia comporta un riesgo: el del ensayo consiste en cohabitar con el error. Su expectativa de vida es, sin embargo, prolongada, porque lo que confiesa imposibilidad de demostración irrefutable también está amparado por la imposibilidad de refutación rotunda. Por eso un ensayo no muere totalmente sino cuando la ciencia se posesiona de todos los problemas que plantea y los trata "correctamente".

El ensayo es una tentativa ambiciosa que no se deja intimidar ni por las grandes preguntas ni por las modestas respuestas a dichos interrogantes. Se trata de una tentativa de rigurosidad allí donde la rigurosidad pura es imposible o donde la ausencia de rigor no es fatal.

Después de este introito el trabajo continúa con unas reflexiones sobre el espíritu de ortodoxia en el que peligra todo creyente. Se aborda la manera cómo las ortodoxias y los ortodoxos habitan la universidad (II) para mostrar luego cómo se utilizan allí los arcaicos mecanismos religiosos del chivo expiatorio y de la demonización del adversario (III). La posición de intelectuales subalternos que no producen o desconocen los procesos de producción de las "verdades" que profesan y transmiten, lleva normalmente al uso dogmático y no instrumental del conocimiento, al ejercicio "sacerdotal" de una autoridad que sobrevalora el respeto, la obediencia y la sumisión (IV), al empleo mágico y ritual de un lenguaje estereotipado y sacralizado (V) y al empobrecimiento de los procesos "iniciáticos" educativos (VII). El capítulo VI muestra que hasta las paredes de la universidad hablan de fe, esperanza, resurrección final, Apocalipsis, martirios y Mesías. Finalmente se trae a colación la vieja analogía del maestro como sacerdote y santo laico para señalar tanto su fundamento como su ambigüedad (VIII).

Antes de que el amable lector se adentre en las páginas siguientes le hago una advertencia que ya Carlo Cipolla formulara en la introducción a su libro Literacy and Development in the West: hasta las plumas de los mejores autores parecen secarse

\footnotetext{
${ }^{34}$ Donde dada la tradición del chisme y del rumor, abundante en la UPN, se saben ciertas verdades que nunca se encontrarán en los documentos o reuniones oficiales.

${ }^{35}$ Reuniones que en su mayoría sólo sirven para diluir responsabilidades y a las que, dado su número, se asiste con frecuencia sin preparación, dispuestos a improvisar sobre la marcha. Tan asiduas reuniones, parte sustantiva del "claustro académico", evocan al claustro por antonomasia: el monacal.
} 
cuando tratan los problemas de la escuela. Ojalá que después de haber leído este ensayo el lector no se arrepienta de haber aprendido a leer y no maldiga el día en que yo aprendí a escribir.

\title{
II. El espíritu de ortodoxia
}

\begin{abstract}
En cierta ocasión salió el diablo a pasear con un amigo. De pronto vieron ante ellos a un hombre que estaba inclinado sobre el suelo tratando de recoger algo.

- ¿ Qué busca ese hombre?, le preguntó al diablo su amigo.

-Un trozo de verdad, respondió el diablo.

- ¿Y eso no te inquieta?, volvió a preguntar el amigo.

-Ni lo más mínimo, respondió el diablo. Le permitiré que haga de ello una verdad religiosa.
\end{abstract}

Dentro del proyecto de modernización del Estado adelantado por el primer gobierno liberal de Alfonso López Pumarejo (1934-1938) se prestó especial atención al problema educativo. Fue así como en 1936 se creó en Bogotá un instituto mixto de carácter estatal, la Escuela Normal Superior, cuyos aportes serían notables en el campo de la ciencia y la cultura en el país.

"El interés central de esa institución lo constituyó la formación de maestros con un alto nivel académico, y en un diálogo permanente entre las ciencias y las humanidades, tratando de retomar las experiencias de la Escuela Normal Superior de París y la Facultad de Ciencias en Alemania; a ello contribuyeron un grupo de profesores europeos, que abandonando sus países por el ascenso del fascismo, se vincularon a la enseñanza en la Normal, haciendo de ella un epicentro de difusión de las modernas corrientes de pensamiento científico (...)

Sin embargo, la Normal no alcanzó más de 15 años de existencia. Una vez retomado el poder por el Partido Conservador en 1946, se inició un proceso de desmonte de la Normal, el cual va desde el recorte gradual del presupuesto, hasta las hostilidades personales hacia sus profesores y alumnos, a los contenidos que allí se enseñaban y a la orientación pedagógica que la inspiraba; finalmente, en septiembre de 1951, Laureano Gómez, a través del Decreto 1955, separa la Normal en dos instituciones, una masculina y otra femenina, que quedaron funcionando en Tunja y en Bogotá, respectivamente, y que darán pie posteriormente al surgimiento de dos Facultades de Educación (Universidad Pedagógica Nacional de Bogotá y Universidad Pedagógica y Tecnológica de Tunja); la verdad es que además de las razones de índole moral (que la educación mixta era peligrosa para la juventud) que se argumentaron para el desmonte de este importante experimento pedagógico, intervinieron discrepancias políticas e ideológicas, que llevaron a sus miembros a dispersarse por todo el país y el exterior"36

\footnotetext{
${ }^{36}$ Martha Herrera, Carlos Low y Hernán Suárez. "La Escuela Normal Superior. Entrevista a José Francisco Socarrás” en Educación y Cultura (Revista del Centro de Estudios e Investigación Docente de la Federación Colombiana de Educadores) Bogotá, abril de 1986, número 7, pp. 20-21.
} 
La Universidad Pedagógica Nacional surge, pues, como un contraproyecto para hacer frente a los avances del proyecto pedagógico de la "Revolución en Marcha" y regresar así a la "recta doctrina y a las sanas costumbres" tal como las concebían el partido conservador y la Iglesia católica, que por aquellos tiempos era una especie de partido conservador en oración ${ }^{37}$. A ese contraproyecto que se sustentaba en la ortodoxia cristiana, el autoritarismo prusiano y "la moral de las faldas tobilleras" se le llama familiarmente en la UPN la pedagogía germano-boyacense pues tuvo, entre otros, a sus inspiradores ideológicos en el alemán Julious Sieber y el boyacense Rafael Bernal Jiménez, y a su mayor intérprete político en el ex ministro conservador boyacense Rafael Azula Barrera ${ }^{38}$.

Para 1969, durante la rectoría de Jaime Sanín Echeverri ${ }^{39}$, se consagró a Teresa de Avila como patrona de la UPN y en uno de sus patios se colocó un busto de la santa. Aquéllos eran tiempos de agitación universitaria a nivel mundial, continental y nacional. Los estudiantes no perdían oportunidad para protestar contra ese acto "retrógrado", hasta que llegó el día en que un exaltado dirigente estudiantil le quebró de un puño la nariz a la estatua y, de paso, se rompió su propia mano. Para evitarle nuevos desaires a la santa, su busto emigró a los jardines del Instituto Pedagógico Nacional, dependencia de la UPN, donde se encuentra actualmente.

Lo curioso es que los estudiantes rechazaron a una santa para adoptar como patrono a un nuevo santo de la izquierda cristiana: el cura guerrillero Camilo Torres Retrepo, muerto en combate en 1966 a los 37 años.

En la plazoleta central de la Universidad, lugar de todas las concentraciones estudiantiles, se levanta, para las arengas y discursos, un púlpito, en cuya base hay incrustada una placa en memoria de Camilo Torres. Antes de toda procesión laica de importancia (que no otra cosa son las manifestaciones de protesta que recorren ordenadamente calles y avenidas coreando cantos y consignas a la manera de las antiguas letanías) el estudiantado se reúne pacíficamente para asistir a una misa celebrada por el capellán de la universidad; el ritual eucarístico, así sea por el fugaz instante de su duración, apacigua los espíritus y coloca a los participantes en un plano superior al de las contingencias históricas, que muy pronto los volverán a dividir.

De unanimidades ortodoxas cuya obligación es olvidar la razón del otro está llena la universidad, como si estuviera condenada a ser fiel a sus orígenes. Es en ese olvido

\footnotetext{
${ }^{37}$ Recta doctrina y sanas costumbres que, según los conservadores, habían sido puestas en peligro en la Escuela Normal Superior. Escuchemos a Virginia Gutiérrez de Pineda, notable antropóloga, egresada de allí:

"Nos cercaron a todos. Nos quitaron el derecho al trabajo. Sobre todo porque teníamos un estigma: normalistas, vale decir, comunistas, manera de lanzarnos a las tinieblas exteriores.(...)

El hecho de estudiar ciencias sociales era cosa peligrosa, estudiar la problemática era tabú, y más si nos atrevíamos a develar críticamente la realidad nacional (...)

Yo no recuerdo si eran editoriales, pero en El Siglo (n.m. principal periódico conservador del país) se escribía que nosotras éramos promiscuas sólo porque en la Escuela Normal Superior hombres y mujeres estudiaban juntos, y para afrenta sacaban iniciales de las estudiantes. Eran los editoriales más sucios que se puedan imaginar, la manera de extender la deshonra a la institución y acabarla. Eso debió de ocurrir en 1942 ó 1943. Pero nosotras no promiscuábamos (sic), era, hagamos de cuenta las monjitas adoratrices, en la pureza más completa".
}

Martha Herrera. Carlos Low. "Virginia Gutiérrez de Pineda: una vida de pasión, investigación y docencia" en Boletín Cultural y Bibliográfico, Biblioteca Luis Angel Arango, Banco de la República. Bogotá, Volumen XXIV, número 10, 1987, pp. 27 y 29.

${ }^{38}$ Gustavo Téllez lregui. "La Universidad Pedagógica Nacional. Proceso y principios de una Reforma", revista Educación y Cultura, Bogotá, abril de 1986, número 7, p. 34.

${ }^{39}$ Primer rector masculino de la UPN, de filiación conservadora y connotado miembro del Opus Dei. 
forzado de la razón del otro donde reside precisamente la sinrazón propia en la mayoría de los casos, no en la total ausencia de contenido razonable en la postura asumida. $Y$ hay que olvidar la razón del otro, se dice a sí mismo el ortodoxo, porque de lo contrario uno aparece como traidor al propio grupo; "no hay que mostrar fisuras, pues tenemos toda la razón". Se revive, entonces, aun desde la "no creencia" y la defensa de posturas "democráticas" el evangélico "quien no está conmigo (en todo) está contra mí". Lo cual conduce a la intransigencia, el maniqueísmo y la simplificación de los problemas y de las posiciones.

"Izquierda' y "derecha , "progresista" y "reaccionario" se convierten casi siempre en rótulos estereotipados, y por lo mismo arbitrarios, que facilitan la descalificación del adversario y ayudan a saber, en caso de votaciones o firma de manifiestos, quiénes son los "nuestros y quiénes los "otros" ${ }^{\text {. }}$. Pero en este ejercicio no siempre están todos los que son ni son todos los que están. Así como en algunos círculos religiosos se evita el tener que analizar los planteamientos de Marx diciendo "es un ateo", o de Freud espetando 'es un pansexualista", en este recinto universitario es dado escuchar cómo se descalifica a otro con un simple: "es un retrógrado", "es un mamerto", "es un izquierdista", "es un conductista", "es un tecnólogo educativo", etc.

Es interesante observar cómo, al tiempo que se descalifica al otro por su supuesta posición política, uno de los tabúes en la UPN es hacer explícita públicamente dicha posición. Eso no lo hacen, por lo menos en la esfera profesoral ni los conservadores, ni los liberales, ni los marxistas; tal vez por el temor a ser convertidos en "chivos expiatorios". Se vive, entonces, y se "macartiza" a partir de suposiciones. Suposiciones que, no hay que negarlo, pueden tener fundamento en la realidad; pero lo correcto sería que se convirtieran en proposiciones, fruto del debate abierto y del análisis amplio de las diferentes posiciones frente a la realidad social. En los discursos orales y escritos es frecuente oír hablar del "proyecto político" y del "proyecto de sociedad y de ciudadano" que subyace a toda educación; pero, al igual-que en el discurso religioso, de estas generalidades no se pasa; el "proyecto" continúa siendo un misterio, tremendo y fascinante, como lo sagrado.

En los últimos años se ha emprendido en la UPN un necesario y saludable proceso de renovación académica a la que se llama, simplemente, la Reforma. Desafortunadamente, también allí se ha introducido el espíritu de ortodoxia. Lo que se concibió corno un proceso en construcción, crítico y creativo, terminó convirtiéndose para algunos en bandera que se defiende o se ataca, en bloque, como si se tratara de una creencia. Se habla entonces de los "amigos" y de los "enemigos" de la Reforma. Mientras fui decano tuve que acostumbrarme a la pregunta: “¿Usted está a favor o en contra de la Reforma?”. No niego que a veces me parecía estar hablando con reformadores del siglo XVI y que yo era una especie de Erasmo, emparedado entre papistas y luteranos.

Puesto que la intolerancia es incompatible con la idea de universidad, y el espíritu de ortodoxia está en estrecha relación con la intolerancia, nunca esta de más para un universitario reflexionar sobre el tema.

Normalmente se dice que alguien es ortodoxo cuando ni expresa ni enseña nada que no esté conforme a la autoridad de la Iglesia. Por extensión se aplica el término ortodoxo al que no se separa un ápice de la autoridad constituida en el grupo al cual adhiere (así se trate de un partido político o de una corriente de pensamiento). Antes que nada la

\footnotetext{
${ }^{40}$ En un par de elecciones profesionales celebradas en 1987 fui testigo de cómo, aun antes de abrirse las urnas para contar los votos, no faltaron quienes cifras en mano, pregonaron los resultados, pues ellos habían visto quiénes votaron 
ortodoxia es una doctrina de exclusión. Cada ortodoxia opina que es la única buena y la única verdadera. El ortodoxo funciona de acuerdo al dictamen de que cuando la "autoridad" a la cual se acoge declara una opinión como recta y verdadera, eso significa que cualquier opinión diferente no es ni lo uno ni lo otro.

La ortodoxia viene después de la creencia. Un creyente acude a todos los hombres para que compartan su fe. Un ortodoxo recusa a todos los hombres que no comparten su fe.

¿Por qué este endurecimiento, este paso del llamado al rechazo, del convencer al anatematizar? Porque toda creencia tiene un germen negativo:

la misma idea que es medio de reunión también sirve como medio de exclusión: "el que no está conmigo está contra mí". Y porque toda creencia al implantarse se organiza y se defiende. Por eso toda ortodoxia, hasta una "revolucionaria", tiende a convertirse en algo eminentemente conservador ${ }^{41}$.

Cualquier ortodoxia reposa en convenciones, y la primera de todas es que uno debe conformarse con la opinión, ya sea de una mayoría o de un jefe, y una vez que esta mayoría o este jefe se han pronunciado, seguirlos so pena de verse excluido del grupo. El resultado es que la ortodoxia se vuelve cada vez más una convención y se apoya cada vez más en fórmulas estereotipadas ( $j$ sin que los adeptos sepan exactamente de qué están hablando!).

El ortodoxo endurece sus posiciones de creyente pues si uno deja que se critique un punto del programa, ¿por qué no otro punto y así sucesivamente ${ }^{42} \mathrm{~A}$ los ortodoxos irreductibles habría simplemente que recordarles las palabras del emperador Juliano: "Limítense a creer; no intenten conocer".

El ortodoxo termina paranoico; ve enemigos por todas partes. Lo que lo lleva a cultivar un espíritu de "ghetto" y una mentalidad de conspirador que se retira o se calla al aproximarse alguien "extraño" al propio grupo.

En pocas palabras, el ortodoxo acaba por utilizar la inteligencia como un arma y no como una luz.

\section{El chivo expiatorio y la demonización del adversario}

Después de ofrecer su novillo por el pecado como expiación por sí mismo y por su casa, tomará Aarón los dos machos cabríos y los presentará ante Yahvé, a la entrada de la Tienda de Reunión. Luego echará suertes sobre los dos machos cabríos, una para Yahvé, y otra para Azazel. Presentará el macho cabrío sobre el cual haya caído la suerte "para Yahvé" ofreciéndolo

\footnotetext{
${ }^{41}$ Los mismos adeptos lúcidos del marxismo, tan difundido en los círculos universitarios, son conscientes de esto. Ya en 1956, durante el XX Congreso del Partido Comunista Italiano, Lucio Lombardo Radice planteaba lo siguiente:

"De hecho no existe ninguna 'verdad' completa, total. La realidad es demasiado complicada para la mente del hombre, incluso para la mente colectiva del hombre, para la ciencia. La verdad se mueve constantemente, crece y cambia. Por eso toda verdad, toda teoría, todo experimento que procura nuevos conocimientos es unilateral o a lo más plurilateral, pero nunca total. Si se aplica el marxismo al marxismo, se llega a la conclusión de que éste tiene sus lagunas necesarias, sus inevitables limitaciones y de que, por tanto, el marxismo debe completarse y desarrollarse con la ayuda de otras verdades limitadas también a su modo, pero complementarias de alguna manera para él".

${ }^{42}$ Entre muchos otros puntos de una comunicación escrita dirigida a los profesores al comenzar el segundo semestre de 1987, el rector de la UPN opinó que le parecía que se debía revisar la manera como estaba funcionando en la universidad el método de los "seminarios". Algunos profesores reaccionaron entre temerosos y airados, manifestando que el rector estaba en contra de "la Reforma" e iba a desmontarla.
} 
como sacrificio por el pecado. El macho cabrío sobre el cual haya caído la suerte "para Azazel", lo colocará vivo delante de Yahvé para hacer sobre él la expiación y echarlo al desierto, para Azazel ${ }^{43}$

Levítico 16, 6-10

El fenómeno del chivo expiatorio ${ }^{44}$ expresa la propensión fundamental entre los humanos a desembarazarse de sus propias faltas a expensas de una víctima. Cada uno trata de echar sobre los hombros del otro la responsabilidad de todos los males e injusticias que padece sin estar dispuesto a asumir su propia parte de responsabilidad.

El mecanismo funciona también a nivel colectivo. Todas las instituciones humanas reproducen, por intermedio de nuevas víctimas, un linchamiento reconciliador. Sobra anotar que el linchamiento no tiene que ser necesariamente físico; hay maneras más sutiles y "civilizadas" de linchar.

Esta actitud de "yo no fui", "ese asunto no es conmigo", "busquemos y señalemos al malo", abunda en la UPN. Lo que he visto es una enorme resistencia a evaluarse o ser evaluado $^{45}$, aunque se está muy presto (por oficio de maestro) a evaluar a los demás y a buscar culpables. Por lo general para los profesores el mal está en los administradores de la universidad, burócratas que no entienden nada de la vida académica. Por su parte la administración da la impresión de que su misión es" salvaguardar los intereses de la universidad" frente a un cuerpo profesoral mediocre y que trata de ganarse el sueldo sin mayores esfuerzos. Los profesores piensan que no se puede mejorar gran cosa el nivel académico porque los alumnos son malos. Los alumnos piensan lo mismo, pero al revés. Al hablar sobre el pasado no remoto de la universidad no es raro escuchar cómo se carga sobre los hombros de $\mathrm{X}$ rector, o de su asesor jurídico, toda la culpa de los males del profesorado. En el año que acaba de transcurrir hemos podido ser testigos de manejos conspiratorios "para obtener la cabeza del rector" (la expresión no es mía) o la de dos de los tres decanos. El anecdotario podría ampliarse, pero no es necesario. Lo necesario es que en vez de andar a la búsqueda de chivos expiatorios, nos acostumbremos a los análisis serenos, pormenorizados y racionales; es esto lo que debe caracterizar al ámbito universitario. Sin el necesario beneficio de inventario, las cosas parecen funcionar bajo el signo de un nuevo aforismo jurídico: "las personas son culpables mientras no demuestren lo contrario". Termina entonces imponiéndose un clima de desconfianza mutua y de poca afección por la universidad.

Sin mencionar ni santos, ni milagros ofrezco algunos elementos que pueden ayudar a comprender cómo funciona este mecanismo del chivo expiatorio y por qué ilustrados universitarios recurren todavía a tan arcaico expediente.

El sacrificio del chivo de turno lleva a cabo una verdadera operación de transferencia colectiva que se efectúa a expensas de la víctima y que obra sobre las tensiones internas, los rencores, las rivalidades y todas las veleidades recíprocas de agresión en el seno de

\footnotetext{
${ }^{43}$ Azazel es el nombre de un demonio que los antiguos hebreos y cananeos creían habitaba en el desierto, tierra estéril, donde Yahvé no ejercía a su acción fecundante.

${ }^{44}$ Para un tratamiento sugestivo del tema véanse los libros de René Girard. La Violence et le Sacré (Grasset, Paris, 1972) y Des choses cachées depuis la fondation du monde (Grasset, Paris, 1978).

${ }^{45}$ Resistencia que tiene sus fundamentos económicos. Dado que la mayor parte del profesorado tiene contratos a término fijo, cualquier tipo de evaluación genera la sospecha de que la administración está buscando excusas para prescindir del servicio de algunos profesores. El asunto me recuerda la ironía con la que Marx anotaba que la Alta Iglesia de Inglaterra no tenía inconvenientes en que se discutieran 9 de sus 10 artículos de fe, pero no toleraría que se tocara una décima parte de sus ingresos.
} 
la comunidad. El sacrificio polariza sobre la víctima los gérmenes de disensión esparcidos por todas partes y los disipa al proponer un apaciguamiento parcial con la eliminación de ella.

Donde hay víctima propiciatoria no hay que urgar mucho para encontrar disensiones, querellas, celos y rivalidades entre quienes conforman el grupo. Ese es un denominador común. Y se espera que el sacrificio de la víctima elegida restaure la armonía de la comunidad, refuerce la unidad social, una los corazones y restablezca el orden. Pues la oposición de cada uno contra cada uno es sustituida por la oposición de todos contra uno. El "caos" de múltiples conflictos particulares es reemplazado por la simplicidad de un antagonismo único: de un lado está el grupo y del otro la víctima por medio de la cual se busca un efecto de reconciliación que resulta de esta polarización unánime.

Paradógicamente, en su calidad de fuente aparente de toda discordia y concordia, la víctima escogida termina siendo magnificada y revestida de un halo sagrado, pues con su inmolación pasa por responsable del regreso a la calma así como había sido juzgada responsable única del anterior desorden. El grupo se percibe, pues, perfectamente pasivo frente a su propia víctima que aparece, por el contrario, como el único agente responsable de la situación.

Por otra parte, de la víctima termina siendo más importante la idea que de ella se hacen que lo que ella es en realidad. Lo cual está determinado por la eficacia del mecanismo victimario: ¿cómo no creer que esta víctima es realmente la causa de todos los desafueros de que se le acusa puesto que basta eliminarla para hacer que retornen el orden, la paz y la concordia? Es el juego de una víctima bien mala, bien capaz de desorganizarlo todo para en seguida, reorganizarlo todo tras su desaparición. No hay que ser muy agudo para percatarse que sacralizar así a una víctima conduce a sacralizar (o es haber ya sacralizado) la acción política y la manera de abordar los ineludibles conflictos que se presentan en la humana convivencia.

Un ejemplo extremo de esta sacralización de los conflictos lo tenemos en el exorcismo de la rectoría de la universidad a fines de 1978. Dejaba entonces la rectoría un liberal y lo reemplazaba como rector encargado un conservador, uno de cuyos primeros actos de gobierno consistió en traer un sacerdote exorcista ${ }^{46}$ para sacar al demonio de la oficina de su predecesor. A nivel simbólico se trata de algo extremadamente serio: ya no basta cargar al otro con el peso de toda la culpa, hay que convertirlo en el Mal mismo.

Más que con las personas, esta demonización se lleva a cabo con las posiciones teóricas que aquéllas asumen ${ }^{47}$, dependiendo el proceso inquisitorial no de análisis académicos exhaustivos y serenos sino de modas intelectuales que se vuelven hegemónicas en determinado momento y que a su vez terminan en la picota, pues el destino de toda moda es dejar de serlo.

\footnotetext{
${ }^{46}$ El entonces capellán de la universidad se negó a llevar a cabo el exorcismo.

${ }^{47}$ Una respetada profesora de la universidad me comentó cómo, a su regreso de los Estados Unidos, donde se había especializado en tecnología educativa, se esparció el rumor de que era agente de la CIA y de que había participado en la reunión de Punta del Este, sin que ella supiera dónde quedaba ese lugar. Hace unos años, al caer en desgracia la "tecnología educativa" en la universidad, aquellos que habían sido sus defensores se vieron sometidos a interrogatorios agresivos en los que se les pedía cuenta sobre sus posiciones. Ellos eran, simplemente, los chivos expiatorios de turno. No serían ni los primeros ni los últimos en pasar por el banquillo de los acusados. Banquillo que a veces se puede ocupar gracias a la ignorancia de los nuevos inquisidores, tal como sucedió a unos profesores de la Facultad de Educación que hace un par de años se vieron acusados de enseñar las teorías de un comunista ruso de apellido Malinowski. ¡Se trataba de Bronislaw Malinowski, eximio antropólogo británico de origen polaco, cuyas investigaciones pusieron las bases metodológicas del funcionalismo en el campo de la antropología social y cultural!
} 


\section{Maestros tiene la santa escuela que os sabrán responder}

De la lectura del trabajo colectivo "Antecedentes, fundamentos y desarrollos de la Reforma Académica de la Universidad Pedagógica Nacional”48 queda clara la crítica a una cierta formación en la que impera "una concepción del maestro como simple transmisor de un saber específico", formación destinada a producir educadores capacitados "en una práctica didáctica de tipo reproductivista" ${ }^{49}$.

Precisamente una de las intenciones de la reforma académica emprendida en la UPN en estos últimos $\operatorname{anos}^{50}$ es la de promover la formación de un educador que no sea un mero e ingenuo transmisor de saberes constituidos; para ello se habla de combinar docencia e investigación ${ }^{51}$, y de llevar a cabo innovaciones pedagógicas tendientes a formar docentes críticos y creativos ${ }^{52}$. La formulación de esta utopía pone de manifiesto que lo que se da es una realidad de signo contrario. Por lo general los maestros se limitan a transmitir una tradición de "verdad" en un lugar llamado "aula". Obran así al igual que Pablo de Tarso, quien definía su misión evangelizadora como un "entregar lo que a él se le había entregado".

En la UPN, puesto que es una universidad pedagógica, lógicamente la preocupación central está en la transmisión de unos saberes más que en los problemas relativos a la constitución de una determinada ciencia. Por eso, aun respetando la especificidad y la necesidad del trabajo pedagógico, merecen tenerse en cuenta las siguientes reflexiones de Theodor Adorno:

"El problema de la inmanente falsedad de la pedagogía reside en que recorta la cosa tratada a la medida de los receptores, y no constituye un trabajo puramente objetivo por la cosa misma. Es más bien un trabajo 'pedagogizado'. Ya por esta sola razón deberían los niños sentirse inconscientemente engañados. No solo transmiten (los maestros) receptivamente algo ya establecido sino que su función mediadora, como tal, de antemano algo sospechosa desde el punto de vista social como todas las actividades de circulación, atrae cierta aversión general. Max Scheler decía una vez que él se comportó pedagógicamente por la sencilla razón de que nunca había tratado a sus alumnos en forma pedagógica. Si me permiten ustedes la referencia personal, mi experiencia corrobora por entero ese punto de vista" ${ }^{3}$.

En este proceso de transmisión de una verdad que él no elabora $\mathrm{y}$, a veces, no comprende, el maestro, como el cura, asume su papel de intelectual subordinado y se vuelve "más papista que el Papa", es decir, ortodoxo rígido.

\footnotetext{
${ }^{48}$ AA.V.V., Antecedentes. Fundamentos y desarrollos de la Reforma Académica de la Universidad Pedagógica Nacional, UPN, Oficina de Planeación, Bogotá, septiembre de 1986.

${ }^{49}$ Oc. pp. 18-19.

${ }^{50}$ Los principios de la Reforma Académica se traducen en un modelo) curricular cuya estructura global se contempla en el Reglamento Académico adoptado por el Consejo Superior de la Universidad mediante el Acuerdo 072 del 22 de junio de 1982.

51 "Aunque una de las funciones de la Universidad es transmitir conocimientos, otra, y tal vez la mas importante, es proporcionar el espacio y los elementos para el desarrollo del pensamiento y la actividad investigativa.

En este Sentido la vinculación entre investigación y docencia reactiva la producción del conocimiento, pues quien investiga transmite pasión por el saber. En el caso concreto de la UPN esta vinculación adquiere mayor significado por cuanto la labor de profesores y estudiantes se centra justamente en lo educativo". Oc. p. 28.

${ }^{52}$ Formar un educador dentro de esta perspectiva de innovación, implica hacer de él una persona autónoma, crítica, que asume posiciones claras frente a la sociedad, la cultura y el mundo, que es consciente de su función transformadora de la realidad y del papel que habrá de jugar en la misma como agente de la tradición cultural y creador de cultura, con una clara formación política y muy definidos derroteros ideológicos, esto es, como un auténtico trabajador de la cultura" O.c. p.31.

${ }^{53}$ Theodor Adorno. "Tabúes relativos a la profesión de enseñar", conferencia pronunciada en el Instituto de Investigación Docente de Berlín el 21 de mayo de 1965 y reproducida en el libro Consignas, Amorrortu editores, Buenos Aires.
} 
Los maestros, como los sacerdotes, tienen tendencia a hablar de verdades eternas ${ }^{54}$ que por lo general no son tales, y aprovechan la autoridad que otorga no sólo el saber más sino el tener la ventaja de que nadie pueda contradecirlos (como el cura desde el púlpito, el maestro también puede hablar ex cathedra) ${ }^{55}$.

Por lo demás, tampoco es extraño encontrar "maestros" que, como buenos adultos, "no conocen otra razón que la fuerza y la prioridad que da la edad, el haber llegado antes y haberse aprovechado de tal ventaja para organizar el mundo a su manera" ${ }^{\circ 6}$.

En un trabajo reciente sobre "La problemática de la evaluación en Colombia", un grupo de expertos educativos bajo la coordinación del Ministerio de Educación Nacional y de la Universidad Pedagógica Nacional planteaba lo siguiente:

"En el sistema educativo merece mencionarse la verticalidad que ha caracterizado la legislación emanada del Ministerio de Educación, que contrasta con la apertura democrática que actualmente se plantea por la vía de la descentralización administrativa y la participación ciudadana. En opinión de representantes de Fecode, los maestros no participan en la elaboración de políticas, en la gestión de propuestas y en el diseño de programas e instrumentos educativos.

"La verticalidad de la administración del sistema educativo se refleja en el funcionamiento de la institución escolar: los jefes de Distrito o zona imparten políticas y recomendaciones a los supervisores, quienes las transmiten a los directores, quienes a su vez, las comunican a sus profesores, sin discusión y sin posibilidades de generar acuerdos que conduzcan a unificación de criterios. Los maestros, por su parte, verticalmente reciben y traducen las políticas educativas en imposiciones a los estudiantes y a los padres de familia, quienes son espectadores pasivos del transcurrir de los procesos educativos que se generan al interior (sic) de la escuela, y de los cuales ellos son excluidos" $"$.

Lo anterior me recuerda algo que decía, a principios de siglo, un cura de pueblo: "hay mucha obediencia en Boyacá. El pueblo obedece al párroco, el párroco obedece a su obispo y el obispo obedece al Papa "58

Por lo visto, los colombianos tenemos una larga experiencia sobre rígidos sistemas jerárquicos de autoridad y de sumisión que generan o fomentan un "ethos de pasividad" al estimular que se traslade a otras personas gran parte de la responsabilidad de la propia vida. $Y$ no hay que irse a Boyacá ni remontarse a principios de siglo. Escuchemos a Francisco Cajiao, quien ha sido rector de dos colegios y de dos universidades, entre ellas la UPN:

“Lo primero que se enseña al niño pequeño es el 'respeto' absoluto e incondicional por su maestro, independientemente de si éste lo merece o no. El sólo hecho de ser 'el maestro' amerita 'respeto'. Esto rige hasta que se llega al último nivel universitario. De aquí se infiere que el respeto no hay que ganarlo, puesto que viene amarrado al

\footnotetext{
${ }^{54} \mathrm{Y}$ tendencia a confiar en el poder de la palabra que transforma los espíritus. Un antiguo profesor de la UPN me comentaba con gracejo que aquí ya no se trata de que "el verbo se hizo carne" sino de que el verbo se hace cargo".

${ }_{55}^{5}$ No es ninguna novedad para sociólogos e historiadores la observación de que en aquellos grupos en que la profesión docente está unida a cierta autoridad religiosa, es más fuerte el aspecto reverencial en la relación con los maestros.

${ }^{56}$ Fernando Savater. El contenido de la felicidad. Ediciones El País, Madrid, 1986, p. 83.

57 AA.VV. La problemática de la evaluación en Colombia. Ministerio de Educación Nacional Universidad Pedagógica Nacional, Bogotá, mayo de 1987, p. 230.

${ }^{58}$ Citado de Wheeler W. Reginal y Browning E. Webster, Modern Missions on the Spanish Main. Filadelfia. The Westminster Press. 1925, p. 86.
} 
rol. El niño, el adolescente y el joven aprenden en primer lugar que: maestro poder = autoridad lo cual implica automáticamente que obediencia - sumisión - respeto.

La primera enseñanza, pues, es la de saber quién manda y quién obedece, quién sabe y quién no sabe, quién gana y quién pierde" ${ }^{\text {"59 }}$.

Como me lo expresaba con toda naturalidad una profesora encargada de la formación de bachilleres pedagógicos en el Instituto Pedagógico Nacional (dependencia de la UPN): "el curso X es el mejor, son muy dóciles".

Al tratar de sortear el escollo del autoritarismo que convierte al educando en un objeto despersonalizado, algunos colegas naufragan en un Laissez Faire educativo que abandona a los alumnos a su propio destino y que confunde la libertad de cátedra con un libertinaje renuente a todo control académico, lo cual conduce fácilmente a que la universidad se confunda con un asilo sagrado para toda suerte de prédicas ${ }^{60}$.

\section{EI lenguaje mágico}

Anotaba Michel Foucault que "cada sociedad tiene su régimen de verdad: es decir, los tipos de discursos que acoge y hace funcionar como verdaderos, los mecanismos y las instancias que permiten distinguir los enunciados verdaderos o falsos, la manera a través de la cual se sancionan los unos y los otros; la técnicas y los procedimientos que están valorizados para la obtención de la verdad; el estatuto de aquellos que tienen el encargo de decir lo que funciona como verdadero". La UPN no escapa a la regla; más aún, para algunos de sus profesores el mismo Foucault se ha convertido en uno de esos "discursos verdaderos", así como para otros grupos de docentes puede serlo Piaget o Freud, Marx o Weber, etc.

Tan fácilmente el lenguaje utilizado se puede convertir en un estereotipo que, en los múltiples debates que se dieron el año pasado en torno al tema de "la Reforma", algunos se dedicaron a "fijar" el vocabulario empleado y a mostrar cómo, mediante un simple juego de combinaciones a partir de unas cuantas palabras "mágicas", se podía producir un discurso "progresista". El conocimiento del vocabulario se convierte así en un sistema de clasificación: ya se sabe que quien emplea tales o cuales palabras es de los "nuestros" o de los "otros", "reaccionario" o "progresista", a favor o en contra de la Reforma. Afortunada, o desafortunadamente, como la realidad es más compleja que el vocabulario, se termina por cometer garrafales equivocaciones sobre quiénes son los "amigos" y quiénes los "enemigos". Por otra parte la historia enseña que cuando de sobrevivir se trata no son pocos los que aprenden rápidamente cuál es el "decir" que conviene ${ }^{61}$,

\footnotetext{
${ }^{59}$ Francisco Cajiao R. La lucha contra la realidad, Bogotá, 1987. p. 19 (policopia).

${ }^{60}$ Las observaciones que a continuación reproduzco corresponden a un estudio sobre la actual universidad española. Cualquier parecido con nuestra realidad no es mera coincidencia.

"La libertad de cátedra en el orden científico no ha sido menor. Cada catedrático puede — por decirlo castizamente- explicar "lo que le dé la gana". Los programas son muy personales, llegando al pintoresquismo más extremado (...).
}

El resultado de esta 'libertad' puede imaginarse; el alumno nunca sabe dónde está, termina la carrera con grandes lagunas y, al tiempo, repite la misma materia en cuatro o cinco asignaturas. Pero el catedrático está muy orgulloso de su libertad de cátedra, que defiende lo mismo frente a intromisiones ministeriales que frente a un control de la Facultad o del Departamento".

Alejandro Nieto. La tribu universitaria. Tecnos, Madrid, 1984, p. 177.

${ }^{61}$ En 1987 parte del vocabulario, cuyo uso garantizaba estar entre los amigos de "la Reforma", era el siguiente: lo fenoménico; lo problémico; lo subyacente; lo hermenéutico; lo cotidiano; lo crítico; lo intersubjetivo; lo inmerso.

Proceso: una constante del proceso; un proceso participativo; insertarse en el proceso (y en la comunidad).

Provecto: p. político; p. pedagógico; p. histórico; la socialización del proyecto y su reconceptualización. 
aunque su práctica continúe sin muchas variaciones. No hay que olvidar que la estereotipia es esencialmente un oportunismo: adaptación —sin convicción — al lenguaje reinante, o más bien a aquello que, en el lenguaje parece regir. Nos encontramos, entonces, con intentos de reforma académica que, en buena parte, quedan reducidos a cambios nominalistas, pues con nombres diferentes cada quien continúa haciendo y enseñando lo que tradicionalmente había hecho y enseñado.

El uso de una jerga erudita y esotérica sirve también para que algunos escondan su poco sentido común, menor experiencia como pedagogos y ninguna claridad conceptual. Ciertamente las ciencias han ido elaborando un lenguaje específico al cual es preciso acceder si se quiere ser especialista en algo; por eso la vida universitaria es, en cierto sentido, un gran proceso de iniciación que culmina con el "espaldarazo", que es la entrega del diploma en la "ceremonia de grado". Lo incorrecto, sin embargo, es utilizar el lenguaje de iniciados para intimidar o confundir a los no iniciados ${ }^{62}$; o, por incapacidad de los hierofantes iniciadores, mantener innecesariamente durante años a los neófitos en el estado de "masa de adeptos" que repiten sin entender (como los acolitos que respondían mecánicamente en un latín que sólo comprendían los sacerdotes $)^{63}$.

\section{Las paredes hablan}

En la universidad una pared limpia es una provocación. Al inicio de cada semestre académico se gastan ingentes sumas de dinero para que los noveles graffiteros encuentren las paredes en buen estado y hagan gala de su limitada imaginación y sentido de la estética.

Pedagógico: el quehacer pedagógico; el saber pedagógico; el discurso pedagógico; el trope pedagógico; los obstáculos pedagógicos; proyecto pedagógico hegemónico y no hegemónico; proyecto pedagógico en construcción.

Discurso: criticidad del d.; reconstrucción del d.; unicidad del d.; niveles significativos del d.; discurso alternativo.

Construcción (reconstrucción y reconceptualización): de un nuevo proyecto histórico; de un discurso pedagógico; de un nuevo sujeto histórico; de un espacio de reflexión; de los saberes.

Todo lo anterior condimentado con frecuentes "al interior de" y "a nivel de".

Meses después el vocabulario se enriqueció con la palabra "el colectivo" (el c. de profesores; el c. de alumnos), término que se utilizó profusamente hace veinte años cuando las revueltas estudiantiles de mayo de 1968 en Francia. En concordancia con el espíritu guerrero que se ha enseñoreado de nuestra sociedad, también han hecho curso en los más recientes debates profesorales: "La trinchera pedagógica", "la estrategia y la táctica a seguir".

${ }^{62}$ Quienes así obran saben que en ciertos ambientes se prefiere continuar en el error antes que confesar humildemente la propia ignorancia $y$ pedir explicaciones. La siguiente anécdota ilustra cuán fácilmente se puede vivir en el reino del equívoco. Durante el primer semestre de 1987, en reuniones amplias donde se discutían los problemas de la UPN, un grupo de profesores puso de moda el término Weltanschauung (que significa visión de mundo, cosmovisión). Después de varias semanas de estar blandiendo algunos el germánico término, un profesor se acercó a pedirme "que le diera bibliografía sobre ese autor Weltanschauung del que tanto se está hablando".

${ }^{63}$ Lo tremendo es que a veces los maestros iniciadores tampoco saben de lo que hablan. Hace poco un grupo de estudiantes me abordó en uno de los pasillos de la universidad para preguntarme cúal era la diferencia entre "materialistas" e "idealistas". Al inquirir, a mi vez, por qué estaban interesados en el tema, me respondieron que estaban confusos pues un profesor les había explicado que los materialistas también eran idealistas ya que "usaban conceptos, y los conceptos eran abstracciones y no cosas materiales". Quedaban así despachadas alegremente centurias de pensamiento filosófico.

Es de maravillar la tranquila seguridad con la cual muchos estudiantes utilizan sentenciosamente un lenguaje cuyo real significado ignoran. En los últimos años me he dedicado sistemáticamente a preguntar en clase por conceptos de amplia circulación entre los jóvenes universitarios, por ejemplo: dialéctica, plusvalía, ideología, estructura social, clases sociales, revolución. He terminado encontrando muchas creencias y pocas ideas claras y distintas. 
Los graffitis oscilan entre la procacidad (sobre todo en los baños), la protesta y la profecía. Por lo menos un ochenta por ciento de las leyendas que se hallan en los corredores y salones de clase son gritos de fe política emitidos por diferentes grupos de izquierda que han sustituido el mito cristiano de la salvación futura por el mito socialista de la revolución salvífica ("Viva el marxismo-leninismo-maoísmo, la ciencia de la Revolución"; "Mujer: tu ideal al servicio de la Revolución"), y que han convertido a Moscú o Pekín en la nueva Jerusalén.

Del simple grito de protesta ("Contra el estatuto antiterrorista"; "No más masacres"; "Fuera la bota militar de las universidades"; "No vote") se pasa a expresiones apocalípticas ("Esta generación está en peligro/ se siente en el aire/ ya se sabe que quieren liquidarla "; "Esta generación tiene enemigos peligrosos. Los que ya no tienen salida han decidido liquidarla") que reclaman actitudes martiriales ("Por la vida hasta la vida misma") y la creyente esperanza en un mañana mejor ("Mujer: de ti nace la esperanza de ser libres") esperanza animada por una expectativa mesiánica ("Son tantos los que día a día no aparecen que un día no cabrán en el subsuelo y brotarán para vengar a la patria "; "Viva el joven e irreverente Mao Tse Tung"; "Avanzar por el sendero trazado por Mao Tse Tung') de la que no está ausente la idea de resurrección y de triunfo final ("El Che vive"; "Camilo vive"; "Pardo Leal: semilla de libertad") propia de una tradición optimista de la que hace parte el marxismo.

"Por tradición optimista hay que entender aquí la amplia cofradía de 'el hoy es malo, pero el mañana es nuestro', de quienes amontonan las escorias presentes para trepar sobre ellas y alcanzar lo que pende más allá, los que soportan más o menos iluminadamente su actual desahucio confortados por la contemplación del plano de la parcelita y el chalet que tienen en la urbanización por venir. Ese optimismo, en religión, se expresa como fe en la trascendencia y, en lo secular, se expresa como confianza en el progreso: en todo caso, responde a la vivida emoción de que el tiempo nos va a ser cada vez más propicio, de que lo peor ha pasado ya y de que ahora vamos a entrar por fin en la única era realmente favorable: el futuro" ${ }^{\prime}$

Que el pensamiento marxista que anima los graffitis de la universidad esté emparentado (sin saberlo) con visiones religiosas del mundo, es algo que no debe extrañarnos. Estas conexiones ocultas que nos remiten a la larga duración ya han sido puestas de manifiesto por estudiosos de la historia de las religiones.

"Marx retorna uno de los grandes mitos escatológicos del mundo asiáticomediterráneo, es decir, el papel redentor del Justo (en nuestros días, el proletariado), cuyos sufrimientos están llamados a cambiar el estatuto ontológico del mundo. En efecto, la sociedad sin clases de Marx y la consiguiente desaparición de las tensiones históricas encuentran su más exacto precedente en el mito de la Edad de Oro, que, de acuerdo con tradiciones múltiples, caracteriza el comienzo y el fin de la Historia. Marx ha enriquecido este mito venerable con toda una ideología mesiánica judeocristiana: por una parte, el papel profético y la función soteriológica que concede al proletariado; por otra, la lucha final entre el Bien y el Mal, que puede fácilmente ponerse en relación con el conflicto apocalíptico entre Cristo y el Anticristo, seguido de la definitiva victoria del primero. Incluso es significativo que Marx recoja en su doctrina la esperanza escatológica judeocristiana de un fin absoluto de la Historia; en esto se separa de otros filósofos historicistas (por ejemplo, Croce u Ortega y Gasset), para los que las

\footnotetext{
${ }^{64}$ Fernando Savater. "Más allá de la utopía: el mito" en Para la anarquía y otros enfrentamientos. Ediciones Orbis, Barcelona, 1984, p. 36 .
} 
tensiones de la Historia son consustanciales a la condición humana y, por tanto, no pueden ser abolidas jamás totalmente" 65 .

En nuestro medio este escatologismo mesiánico marxista encuentra terreno abonado en una larga historia de mesías y de profetas que se han dado en las sociedades ibéricas, impregnadas del mensaje cristiano de la salvación y la liberación apetecibles.

Al grito de "Dios lo quiere", se han movilizado en nuestra historia innumerables personas cuando tratan de sacudir su miseria y opresión, sacando de la supuesta voluntad divina fuerzas y esperanzas para el levantamiento. A los ojos del pueblo creyente para realizar la proeza utópica de operar un trastorno social completo se requieren hombres providenciales, personas a través de las cuales actúe justicieramente el brazo poderoso de la Providencia. Tal vez indagando en esta dirección encontremos pistas para explicarnos, en la historia latinoamericana, el arraigado culto al caudillomesías, llámese Bolívar, Perón, Gaitán, Fidel Castro, Che Guevara o Camilo Torres ${ }^{66}$.

\section{Iniciaciones librescas}

Todas las sociedades necesitan y tienen sus rituales de iniciación. A través de los procesos iniciáticos los jóvenes novicios entran en conocimiento de las actitudes, técnicas e instituciones de los adultos, así como también de los mitos y tradiciones sagradas de la tribu, nombres de los dioses e historia de sus obras; es decir, se le revela gradualmente al joven, en el curso de su iniciación, una "concepción de mundo".

Pero la iniciación no se queda en un simple proceso de instrucción, de acumulación de conocimientos. Mediante la iniciación, y por un conjunto de ritos y revelaciones orales, se logra una modificación radical del ser del sujeto iniciado que adquiere así condición de miembro responsable de la sociedad. La iniciación es un proceso que modifica el régimen existencial del iniciado y que lo saca de la masa de los "profanos" integrándolo en una comunidad de "elegidos" 67 .

El paso por la universidad puede ser analizado como un proceso de iniciación que constituye una experiencia decisiva en la vida de individuos que, gracias a dicha experiencia, "maduran" antes de asumir plenamente sus responsabilidades profesionales en la sociedad.

En los rituales y revelaciones orales de "iniciación universitaria" los profesores son una especie de hierofantes que ejercen la función de instructores y revelan a los discípulosnovicios los secretos del oficio, los conocimientos y la "visión del mundo" propios del gremio de elegidos "licenciados", "magísteres" o "doctores" al que pertenecerán. Sin embargo, estos procesos iniciáticos se han convertido en algo de una impresionante pobreza pues se reducen, en gran parte, a instrucciones librescas, no tocan a la totalidad

\footnotetext{
${ }^{65}$ Mircea Eliade. Mito y Realidad (título original: Aspects du Mythe, Paris, 1963). Ediciones Guadarrama, Madrid, 1973, p. 202.

${ }^{66}$ Sobre el tema véase Jacques Lafaye, Mesías, cruzadas, utopías. El judeo-cristianismo en las sociedades ibéricas. Fondo de Cultura Económica, México, 1984.

Para una introducción al tema se leerá con provecho la obra de Mircea Eliade. Iniciaciones místicas. Taurus, Madrid, 1975 (título original: Birth and Rebirth Nueva York, 1958).

${ }^{67}$ Para una introducción al tema se leerá con provecho la obra de Mircea Eliade. Iniciaciones místicas. Taurus, Madrid, 1975 (título original: Birth and Rebirth Nueva York, 1958).
} 
de la persona y, me atrevo a sugerir, en muchos casos no responden a una profunda experiencia personal de los maestros iniciadores.

La educación —incluida la universitaria - entendida como un proceso de iniciación, implica cultivar a la persona toda. No sólo su cerebro sino también su corazón, su capacidad de amar, de desear, de imaginar, de sentir, de integrarse a la colectividad y de mejorarla. Educar-iniciar es, pues, socializar; es decir, incorporar a una totalidad, con su universo de conocimientos, ideales y valores.

En cuanto a esas iniciaciones que se caracterizan por reducirse casi que exclusivamente a una instrucción libresca he observado que se dan, por lo menos, dos posibilidades extremas: la de los que están en la tranquila posesión de una Verdad bien definida y la de los que buscan y transmiten, tanteando entre tinieblas, los restos de verdades que piensan haber encontrado esparcidos en una multiplicidad de libros y de autores.

Si empleamos la "larga duración" que manejan los historiadores encontraremos que ambas posiciones arriba mencionadas tienen remotos antecedentes. Conocemos la leyenda del califa que ordenó la destrucción de la biblioteca de Alejandría argumentando que: o estos libros dicen las mismas cosas que el Corán, y son inútiles, o dicen cosas diversas, y son falsos y dañinos. El califa conocía y poseía una Verdad, y con base en su verdad (la Verdad de su libro sagrado) juzgaba los otros libros.

Por otra parte, el hermetismo del siglo II buscaba una verdad que no conocía y que poseía sólo a través de libros. Por lo tanto imaginaba o esperaba que todo libro contuviera una chispa de verdad. En esta posición sincrética entraba en crisis uno de los principios del modelo racional griego, el del "tercero excluido"68. Muchas cosas podían ser verdaderas al mismo tiempo aunque se contradijeran entre si $^{69}$.

Las aporías planteadas por el califa y por los seguidores de Hermes Trimegisto prosiguen su curso en los pasillos de la Universidad Pedagógica. Entre el dogmatismo del primero y la confusión de los segundos algunos buscan como no salir de Escila para entrar en Caribdis, esfuerzo inútil mientras la realidad se reduzca a la exégesis de uno o de múltiples textos "sagrados" y se siga pensando — desde verdades ajenas y, por eso mismo, literalmente desde la enajenación- que si la realidad no concuerda con la teoría... peor para la realidad.

\section{Un sacerdocio laico}

Al rememorar sus años en la Escuela Normal Superior, la distinguida antropóloga y educadora Virginia Gutiérrez de Pineda recuerda que:

"éramos ascéticos, con votos de pobreza, castidad y obediencia, como se nos inculcaba que debía ser el maestro"70.

\footnotetext{
${ }^{68}$ Principio que se enuncia: "De dos proposiciones contradictorias, una es verdadera y la otra es falsa".

${ }^{69}$ Debo a Umberto Eco la "revelación" que relaciona el asunto del califa con el del hermetismo (véase su discurso de inauguración de la trigésimo novena Feria del Libro, Frankfurt, octubre 6 de 1987).

${ }^{70}$ Herrera y Low, "Virginia Gutiérrez de Pineda: una vida de pasión, investigación y docencia”, O.c. p. 29. 
Entre otras cosas, con la idea del maestro de vida intachable, modelo para jóvenes inmaduros, se le ha obligado al educador a una ascesis del erotismo, mucho más severa que la exigida a otras profesiones. Como anécdota recuerdo que hace unos años se instaló en los alrededores de la UPN un burdel llamado la "Casa Rosada". El Consejo Académico deliberó entonces acerca de si era cierto que los alumnos frecuentaban el lugar, a fin de tomar medidas para proteger la moral de los futuros maestros.

En 1987, lustros después de las experiencias de doña Virginia, en el acto solemne en el cual se condecoró a 43 miembros de la UPN que habían trabajado en ella más de veinte años, el rector de la universidad comenzó su discurso diciendo:

"El magisterio es una especie de sacerdocio. No nos pagan mucho, nos exigen demasiado y, para ser maestro, se requieren profundas convicciones" ${ }^{\text {"71. }}$.

Precisamente porque se está convencido de que los educadores tienen una "misión" muy especial que cumplir en la sociedad, una de las preocupaciones existentes en la universidad es afinar criterios de admisión a través de los cuales se pueda detectar la verdadera "vocación" de los candidatos.

La analogía entre el sacerdote y el maestro es de vieja data y ha sido utilizada por ilustres pensadores que están más allá de cualquier sospecha de querer favorecer con ello una educación clerical. Emile Durkheim, uno de los padres de la sociología, escribió al respecto:

"Lo que crea la autoridad de que tan fácilmente se reviste la palabra del sacerdote, es la alta idea que éste tiene de su misión, porque habla en nombre de un dios, en quien cree, y a quien se siente más próximo que la multitud de los profanos. El maestro laico puede y debe tener algo de este sentimiento. También él es el órgano de una gran personalidad moral que le es superior: la sociedad. Como el sacerdote es intérprete de un dios, él es el intérprete de las grandes ideas morales de su tiempo y su país"72.

Que, por lo menos a nivel de representación colectiva, el maestro sea el heredero del monje, y de éste herede tanto la admiración como el desprecio que al clérigo se profesaba, es algo que Theodor Adorno ha tratado de manera sugestiva en el contexto europeo ${ }^{73}$.

La imagen del "maestro-sacerdote" muestra al educador como una especie de avanzado de la cultura, de luchador incansable contra la ignorancia, sin que le importen los sacrificios espirituales y materiales que se le imponen; un "santo laico", abnegado, desinteresado y tan identificado con su tarea que llega a olvidarse hasta de sí mismo. Aunque con esta imagen la sociedad respalda la autoridad del maestro, desafortunadamente no le otorga a la vez el status ni la dignidad que los "discursos oficiales" parecieran reconocerle. La exaltación poética de este "apostolado" busca ocultar el hecho de que el maestro está condenado a ser —como decía Sarmiento— "el último mono del presupuesto"74.

\footnotetext{
${ }^{71}$ Palabras del señor rector Francisco Cajiao Restrepo. Octubre 21 de 1987.

${ }^{72}$ La cita está tomada de un artículo de Durkheim publicado en el Nuevo diccionario de Pedagogía y de Instrucción primaria (Editorial Hachette, París, 1911), retomado junto con otras tres lecciones suyas por Paul Fauconnet, y publicado bajo el título de Educación y Sociología (traducción castellana en Editorial Linotipo, Bogotá, 1979, pp. 96-97).

${ }^{73}$ Theodor Adorno. Consignas. Editorial Amorrortu, Buenos Aires (capitulo "Tabúes relativos a la profesión de enseñar").

${ }^{74}$ Ricardo Cf. Nassif. Teoría de la Educación, Cincel-Kapelusz, Madrid, 1980, pp. 158-159. 
Para indicar una condición de pobreza, todavía está vigente el refrán español: "Pasa más hambre que un maestro de escuela". Y, puesto que en todos los lugares y épocas la oferta de maestros capaces ha estado en función de los salarios que se les ofrece y del prestigio social que se les atribuye ${ }^{75}$, reclutar a los mejores sin ofrecerles en contraprestación un buen nivel de vida y un status social alto requiere el recurso a dosis masivas de ideología como la del "apóstol social y santo laico".

La imagen del maestro sacerdote no se tiene que reducir necesariamente a la de un servidor acrítico y sumiso de una clase dominante, o del Estado que ésta maneja. La figura del maestro "apóstol" también puede ser portadora de nuevos ideales que se abren paso en la historia.

"Como tal (esta imagen) tuvo vigencia en el momento del esplendor del liberalismo burgués, en el cual gran parte de los maestros se movían convencidos de ser los constructores de una nueva sociedad con el arma de la educación. Se piense como se piense - a cien años de distancia- este fue el móvil de los maestros con los cuales Sarmiento, y los grandes reformadores de la educación latinoamericana del siglo XIX, quiso sembrar la República. Y, más allá del liberalismo, la figura reaparece en todos aquellos pueblos empeñados en levantar nuevas formas sociales, económicas y políticas, unida a la resurrección de la importancia del proceso educativo en las transformaciones estructurales profundas y revolucionarias. Sólo que, en estos casos, la figura del maestro ya nada tiene que ver con la tradicional del ingenuo y empecinado "sacerdote", acercándose en cambio a la de un trabajador que, en un área, se liga con los restantes sectores de la comunidad interesados por la brega cotidiana por la liberación o por la reconstrucción —o la construcción- de una vida más justa. De ahí que - por la naturaleza de su tarea - todo maestro tenga, en efecto, algo de "misionero', aunque comience a tomar conciencia de los límites del apelativo. Con lo cual, lejos de disminuir su importancia, se acrecienta proyectándose sobre regiones intocadas hasta no hace mucho tiempo"76.

Puesto que del amor al odio se cruza presto el umbral, no es raro ver cómo de la exaltación de la educación y del educador como factor "salvífico" de la patria y de la sociedad se pasa también fácilmente al extremo de "demonizarlos" cargándoles, desde la izquierda, la responsabilidad de la reproducción de las desigualdades sociales y, desde la derecha, acusando a los maestros de haberse politizado y de haber abandonado su sagrada y sacrificada misión cuando se niegan a ser los simples legitimadores y transmisores de los valores de un sistema social en crisis y necesitado de profundas reformas.

Si con la cátedra se abrían las puertas de un sacerdocio laico, sus atractivos individuales y colectivos han entrado en crisis, como sucede con el actual sacerdocio católico. Se terminó el respeto mayestático que existía ante el profesor. Se han resquebrajado igualmente las tradicionales reglas rituales; por ejemplo: ya los alumnos no se ponen de pie al entrar el profesor en clase; nadie le cede el paso en los corredores; se lo tutea; se le interrumpe tranquilamente en clase para pedir aclaraciones; se discute con él, y públicamente, cuando no se está de acuerdo. No olvidemos (y no se trata de nostalgias románticas) que las fórmulas rituales y la asignación de papeles (roles)

\footnotetext{
${ }^{75}$ Véase el estudio del historiador italiano Carlo Cipolla, Educación y desarrollo en Occidente, Editorial Ariel, Barcelona, 1983 (título original: Literacy and Development in the West, 1969).

${ }^{76}$ R. Nassif. O.c. pp. $159-160$.
} 
contribuyen a la paz colectiva. Cómo redefinir hoy esos rituales y esos roles en el mundo educativo es algo que debe ocupar un lugar entre nuestras preocupaciones.

Si, la sociedad y la universidad cambiaron. Las nuevas necesidades sociales y universitarias no están hechas a la medida de los antiguos sacerdotes que se ven, muchas veces, portadores de unos ideales que parecen no interesar más. Los valores que los movieron, y aún mueven, ya no son de curso social. Algunos de los más viejos lamentan haber "entregado su vida" a esta causa y miran desconsolados la situación actual. Otros, más jóvenes y sin diferentes posibilidades laborales, parecen haberse resignado a su suerte. De los mismos maestros, y de la voluntad política del Estado y de la sociedad a la cual sirven, dependerá que la crisis no los aniquile sino que los fortalezca. Pueda ser que, como a los toros de casta, el castigo los agrande.

\section{Epílogo}

Algunas de las anotaciones hechas en las páginas anteriores pueden parecer irreverentes. No era mi propósito molestar sino hacer pensar y mostrar cómo, sin darnos cuenta muchas veces, desfilan ante nuestros propios ojos y perduran en nuestras propias vidas comportamientos que, altivamente, juzgamos como supervivencias de una mentalidad arcaica. Por una parte, considero todavía válido el evangélico consejo de mirar la viga en el ojo propio. Por otra parte, en el actual estadio de la evolución humana probablemente sea imposible (y quien sabe si deseable) una razón despojada de todo tipo de elementos míticos y/o religiosos. Hasta los intelectuales se alimentan de ilusiones, así se demuestren infundadas. Sólo les falta la caridad para cumplir en forma con las tres virtudes teologales.

Que la religión y la mitología pervivan bajo formas secularizadas aun en los claustros universitarios, no es algo que deba extrañarnos. El hombre profano es el descendiente del homo religiosus y no puede anular su propia historia. Se trata de comportamientos y formas de ver el mundo que han fraguado a lo largo de milenios. Quiéralo o no, el hombre arreligioso de los tiempos modernos prolonga —desacralizándolos- las actitudes, creencias y lenguaje del homo religiosus. En cierto modo podríamos decir que, en el hombre de las sociedades desacralizadas, la religión se ha hecho "inconsciente"; yace enterrada en las capas más hondas del ser; pero ello no quiere decir que no continúe desempeñando una función esencial en la economía de la psique ${ }^{77}$

Sin desconocer el papel que han jugado y juegan todavía en la vida humana esos elementos religiosos -ocultos o manifiestos - me parece que hay que continuar luchando para que el ámbito denominado "universidad" sea un lugar propicio para el desarrollo de saberes y comportamientos racionales.

Por racionalidad entiendo aquí, tal como recientemente lo ha planteado Jurgen Habermas $^{78}$, una disposición de sujetos dotados de lenguaje y capaces de actuar, que los faculta para adquirir y utilizar un saber falible. Esa racionalidad se mide por la capacidad de los participantes en la interacción para justificar y motivar la necesidad de orientarse

\footnotetext{
${ }^{77}$ Sobre el tema abunda el gran historiador de las religiones Mircea Eliade en varios de sus numerosos trabajos. Sugestivas observaciones se encontrarán en el último capítulo de Mito y realidad (Guadarrama, Madrid, 1968; título original: Aspects du mythe. Paris, 1963) y también en el último capítulo de Lo sagrado y lo profano (Labor, Barcelona, 1967: título original: Das Heilige und das Profane. Hamburgo, 1957).

${ }^{77}$ Cf. J. Habermas. Der philosophische Diskurs der Moderne. Frankfurt a. M., 1985, p. 366.
} 
por aquellas pretensiones de validez que pueden contar con un reconocimiento intersubjetivo.

Se trata, pues, de uña razón falible, que ha depuesto toda pretensión de absolutez y se aventura por ello en una continua búsqueda de verdad, entendida ésta como consenso no coactivo, como resultado de un diálogo libre entre personas libres. Si queremos construir una universidad de nada nos sirve lanzarnos - así sea correctamente - los ladrillos a la cabeza. Lejos está de nosotros, universitarios, la tarea de predicar y dirimir sobre el Bien y el Mal, la Verdad y el Error, utilizando la investidura científica como una nueva forma de brujería. Ya es bastante con analizar atenta y juiciosamente la sociedad en que vivimos, tratar de evitar el planteamiento equivocado de los problemas y no consumir inútilmente energía en su solución.

No faltará quien diga o piense que lo anterior son utópicas esperanzas propias de un pensamiento "criptorreligioso". Si así fuere, no me avergüenzo: la coherencia absoluta es una terrible característica de la intolerancia inquisitorial. 